\title{
Recovery of chlorinated solvent trichloroethylene contaminated groundwater using a hybrid treatment system
}

\author{
C. M. Kao
}

Received: 20 May 2012/Revised: 6 October 2012 / Accepted: 9 December 2012/Published online: 22 January 2013

(C) Islamic Azad University (IAU) 2013

\begin{abstract}
In this laboratory pilot-scale study, a hybrid treatment system has been developed to remove chlorinated solvent trichloroethylene and fine particles from chlorinated solvent trichloroethylene-contaminated groundwater before it is applied for further recovery. The two-stage system contained fiber-ball filtration followed by nanofiltration membrane processes. The measured chlorinated solvent trichloroethylene and suspended solids of the tested groundwater were $850 \mu \mathrm{g} / \mathrm{L}$ and $1,052 \mathrm{mg} / \mathrm{L}$, respectively. Up to $97.3 \%$ of chlorinated solvent trichloroethylene and $99.9 \%$ of SS could be removed by the hybrid system with an operational pressure of $4.1 \mathrm{~kg} / \mathrm{cm}^{2}$. The chlorinated solvent trichloroethylene removal mechanism in the fiber-ball filtration process could be due to adsorption. Approximately 98.2 and $78.6 \%$ of chlorinated solvent trichloroethylene rejection was observed when nanofiltration membrane was used for chlorinated solvent trichloroethylene removal with the recover rate of $80 \%$ and initial chlorinated solvent trichloroethylene concentration of 1 and $10 \mathrm{mg} / \mathrm{L}$. Higher chlorinated solvent trichloroethylene rejection can be obtained when lower chlorinated solvent trichloroethylene concentration $(1 \mathrm{mg} / \mathrm{L})$ was applied. High chlorinated solvent trichloroethylene concentration $(10 \mathrm{mg} / \mathrm{L})$ would increase the pore size of nanofiltration, which causes the decrease in chlorinated solvent trichloroethylene rejection rate. Approximately $46.6 \%$ of flux drop was observed when nanofiltration membrane was used along compared to the system using FF as the first treatment stage. This indicates that the application of fiber-ball filtration could maintain a higher
\end{abstract}

C. M. Kao $(\bowtie)$

Institute of Environmental Engineering, National Sun

Yat-Sen University, Kaohsiung 804, Taiwan

e-mail: jkao@mail.nsysu.edu.tw flux of groundwater treatment. The developed fiber-ball filtration and nanofiltration hybrid membrane system is able to reduce the chlorinated solvent trichloroethylene and solid concentrations to meet the water reuse and groundwater remediation standards.

Keywords Fiber-ball filtration - Groundwater treatment . Membrane · Nanofiltration · Trichloroethylene

\section{Introduction}

In Taiwan, groundwater is a very valuable water resource for both urban and industrial uses. Approximately $30 \%$ of the drinking water and $25 \%$ of all water used come from groundwater. However, groundwater at many existing and former industrial sites and disposal areas is contaminated by chlorinated organic compounds. The chlorinated solvent trichloroethylene (TCE) is one of the most ubiquitous of these compounds. The toxic and persistent nature of TCE poses a serious health threat to humans and ecological receptors (Tsai et al. 2010, 2011). Thus, appropriate groundwater treatment technologies need to be developed after groundwater pumping before the extracted water is delivered for domestic or industrial uses. Chemical oxidation and biological treatment are two commonly used technologies for the treatment of TCE-contaminated groundwater. However, oxidant addition during the chemical oxidation process might cause the secondary pollution problem and the residual oxidants would also limit the further usage of treated groundwater (Zermeño et al. 2011). The lengthy timeframe of the biological treatment would not be possible for immediate groundwater recovery unless a large bioreactor is installed on site for groundwater treatment. 
Membrane technologies have been applied in recent years in different industries for water purification (Hoinkis and Panten 2008; Kan et al. 2012). The dual membrane ultrafiltration (UF)/reverse osmosis (RO) process has been used to improve the quality of the reclaimed water. UF has been replaced by microfiltration (MF) or nanofiltration (NF) in different field applications (Hoinkis and Panten 2008). The UF is usually used for microbial removal and is also useful for large molecule recovery, which makes water recycling more economic (Howell 2004). In the context of pressure-driven membrane processes, the solution-diffusion model was predominantly used for the description of RO. However, it has also been employed for NF modeling (Yaroshchuk et al. 2011).

Compared to traditional physical/chemical treatment processes, membrane processes have the advantages of approving water quality, saving space, saving chemical dosage, reducing sludge from chemical processes, and selectively eliminate physical, chemical, and microbiological contaminants from wastewater (Huang et al. 2010). Thus, using membrane processes is increasingly popular for wastewater reuse applications, and membrane technology is being considered as a reliable option for wastewater reclamation.

The major problems in pressure-driven membrane processes is the reduction of the permeate flux due to membrane fouling, resulting in increased operating costs, and the hydrophilic fraction of the contaminants also has a higher tendency of fouling membranes (Vrouwenvelder et al. 2009). Membrane scaling can lead to not only a severe decline in permeate flux but also a considerably shortened membrane lifetime (Vogel et al. 2010). This contributes to increased operational costs as a result of permeate flux decline and/or increased trans-membrane pressure (TMP) requirements (Peiris et al. 2010). Colloid fouling is one of the major categories of performance deterioration in membrane water treatment processes (Huang et al. 2011). To control fouling, identification and quantification of flocculants in treated wastewater and applying pre-treatment processes have been studied (Fan et al. 2008).

Traditionally, sand filtration has been applied for particle removal. However, the removal efficiency of equivalent particle size for sand filtration system is about $20 \mu \mathrm{m}$. Thus, the efficiency of using sand filtration on clayey or silty particles contained in groundwater would be low. Clogging of sand filtration and limited land space for sand filter tank are two other concerns when it is applied on site. Thus, alternative pre-treatment technology for groundwater purification is required. Fiber ball filtration (FF) has been applied to replace traditional sand filtration and biofiltration for small particle removal in recent years (Huang et al. 2010). Xue et al. (2008) used FF as the pre-treatment unit for hotel wastewater treatment before the dual membrane system (UF/RO) was applied for water reclamation. Results of this study showed that high particle and algae removal efficiency was obtained using the FF pre-treatment unit (Xue et al. 2009; Zeng et al. 2007). Fiber ball filters were used as the filtration materials in the oil refining wastewater recycling process (Zeng et al. 2007). Researchers reported that an effective and efficient particle and floc removal was achieved, and effluent suspended solid (SS) concentration was below $2 \mathrm{mg} / \mathrm{L}$ after the $\mathrm{FF}$ treatment (Zeng et al. 2007).

Membrane systems combining chemical/physical processes (e.g., coagulation/sedimentation, ozonation, chlorination, activated carbon) with membrane unit have been developed (Xie et al. 2011). However, there were few studies used combined membrane system to treat and recycle chlorinated organic compounds contaminated groundwater. In this study, a hybrid treatment membrane system consisting of FF and NF processes has been developed to treat TCE-contaminated groundwater before it can be further treated by $\mathrm{RO}$ unit for domestic or industrial uses. The advantages of this hybrid treatment system included (1) no degradation byproducts, (2) no chemical addition, (3) efficient pollutant removal, and (4) satisfactory water quality after treatment. The objectives of this study were to (1) investigate the characteristics of the tested TCE-contaminated groundwater, (2) evaluate the feasibility of using FF and NF on TCE removal, (3) design a hybrid membrane system for the recovery and reuse of TCE-contaminated groundwater, and (4) evaluate the fouling potential of the applied membrane.

\section{Site description}

A TCE-spill site located in southern Taiwan was selected for this contaminated groundwater purification study. In late 2008, leakage from a TCE storage tank resulted in the groundwater contamination. On-site borings encountered up to $22 \mathrm{~m}$ of mostly brownish and fine to medium sand loam. The average groundwater elevation within the shallow aquifer is approximately $4-6 \mathrm{~m}$ below land surface. The measured effective porosity is 0.35 , and the average hydraulic conductivity for the surficial, unconfined aquifer is $0.011 \mathrm{~cm} / \mathrm{s}$. The measured groundwater temperature in the surficial aquifer varies from 19 to $27{ }^{\circ} \mathrm{C}$.

The preliminary site investigation results (data not shown) indicate that the TCE contamination has become a diffuse pollution, which has resulted in a dispersed TCE plume in the site. The groundwater concentration varied from 0.58 to $1.1 \mathrm{mg} / \mathrm{L}$. Because the site groundwater is pumped for industrial and irrigation uses, the contaminated groundwater needs to be treated and purified on site before 
it can be reused. In the meantime, the treated groundwater needs to meet groundwater remediation standard for TCE $(0.05 \mathrm{mg} / \mathrm{L})$ established by Taiwan Environmental Protection Administration (TEPA) (TEPA 2011).

\section{Materials and methods}

Groundwater sampling and analyses

Groundwater samples were collected from two monitor wells (MW1 and MW2) for the pilot-scale study. Groundwater samples were analyzed for organic compounds and geochemical indicators including $\mathrm{pH}$, conductivity, turbidity, total dissolved solids (TDS), suspended solids (SS), total organic carbon (TOC), ammonia nitrogen $\left(\mathrm{NH}_{3}^{+}-\mathrm{N}\right)$, nitrite $\left(\mathrm{NO}_{2}^{-}\right)$, nitrate $\left(\mathrm{NO}_{3}^{-}\right)$, alkalinity, hardness, chloride $\left(\mathrm{Cl}^{-}\right)$, sulfate (SO), heavy metals, total bacterial count (TBC), and TCE. Sample analyses were performed in accordance with the methods described in Standard Methods (APHA 2005). Ion chromatography (Dionex 600, USA) with an analytical column (IonPac AS-17, $4 \times 250 \mathrm{~mm}$, Dionex) was used for anion and cation analyses. The MP120 pH/Eh meter (Mettler-Toledo) was used for $\mathrm{pH}$ measurement. TOC was analyzed by a Total Carbon Analyzer (Multi N/C 3000, Analytik Jena AG, Germany). Concentrations of TCE were analyzed in accordance with EPA method 601, using a Tekmer Purge and Trap Model LSC 2000 with a Varian Model 3800 gas chromatograph (GC). A $50 \mathrm{~m} \times 0.32 \mathrm{~mm}$ DB-624 capillary column with a $0.25 \mu \mathrm{m}$ film was used for sample separation. In this study, all chemicals were reagent grade (Fisher Scientific, USA).

Hybrid membrane system design and performance evaluation

In this study, the effectiveness of FF on the treatment of collected groundwater was evaluated through a packed bed PVC column experiment. The fiber ball was made of polyester, which can resist high temperature (up to $\left.260{ }^{\circ} \mathrm{C}\right)$, and can be rinsed by acidic $(35 \% \mathrm{HCl} ; 75 \%$ $\left.\mathrm{H}_{2} \mathrm{SO}_{4} ; 65 \% \mathrm{HNO}_{3}\right)$ and basic solution $(10 \% \mathrm{NaOH}$; $28 \% \mathrm{NH}_{4} \mathrm{OH}$ ) (Tsinghua Tongang Co., Beijing, China). The diameter, porosity, and surface area of each fiber ball were $2.5 \mathrm{~cm}, 85 \%$, and $2,000 \mathrm{~m}^{2} / \mathrm{g}$, respectively. Approximately 100 fiber balls were packed in the column for groundwater filtration. Figure 1 shows the schematic diagram of the FF system. A peristaltic pump (Cole Parmer MasterFlex L/S ${ }^{\circledR}$ ) was used to deliver the groundwater into the filter tank. All tubing materials in contact with solution were made of Norprene (A-06402-15, Cole Parmer).
The operational conditions of the FF system are presented in Table 1. In this study, FF was applied as a pre-treatment process for pollutants (e.g., SS, turbidity, and TCE) removal under different operational conditions. The control factors included influent solid concentrations (e.g., turbidity, SS) and filtration velocity. Three different influent turbidity values $(61,177$, and 370 NTU) prepared using kaolin solutions were tested with filter velocities of 6.1, 15.3 , and $27.5 \mathrm{~m} / \mathrm{h}$, respectively. Higher groundwater turbidity values would be observed after storms or rainfalls. Thus, higher influent turbidity values were applied in this study to obtain more conservative results. The operating pressure was approximately $4.1 \mathrm{~kg} / \mathrm{cm}^{2}$. Effluents collected from the column outlet were analyzed for water quality indicating parameters (e.g., turbidity, SS, TCE). Duplicate experiments were performed in this study. The results are presented as the mean \pm standard deviation. Figure 1 presents the schematic diagram of the hybrid membrane system of the pilot-scale study. In this system, the TCEcontaminated groundwater was used as the feed solution. The collected groundwater was treated by FF followed by the membrane module. Each unit consisted of a highpressure feed pump, pressure vessel, and a recirculation loop with a pressure gage and a flow meter. This system was operated in continuous-feed mode with a recycle of concentrate flow to maintain a required minimum concentrate flow. Flows and pressures were controlled by adjusting the feed, recycle, concentrate, and permeate valves. In this study, the feed and recirculation flow rates of the hybrid membrane system were 0.5 and $0.1 \mathrm{~L} / \mathrm{min}$, respectively. The volume of groundwater treated per cycle was $0.44 \mathrm{~L} / \mathrm{min}$. The experiments were carried out using three different types of membrane modules (MF, UF, and NF) [membrane material: polystyrene (PS), thin film composite (TFC) and cellulose acetate (CA), effective membrane filtration area: $114 \mathrm{~cm}^{2}$ (Advanced Biotechnology Laboratories Co. Ltd., Taiwan)]. The flat type membrane (MF, UF, and NF) cartridge has a dimension of $23 \mathrm{~cm}(\mathrm{~L}) \times 13 \mathrm{~cm}(\mathrm{~W})$. The water permeate flux and operating pressure were $7.5 \mathrm{~L} / \mathrm{h} / \mathrm{m}^{2}$ and $3.2 \mathrm{~kg}_{\mathrm{f}} / \mathrm{cm}^{2}$, respectively. Duplicate experiments were performed in this study. The results are presented as the mean \pm standard deviation. Table 2 shows the key characteristics of three different types of membrane modules.

The groundwater used in experiment was sampled from a monitor well (MW) (with TCE concentration of approximately $1 \mathrm{mg} / \mathrm{L}$ ) located inside the contaminated area of the studied TCE spill site. To evaluate the performance of the developed hybrid membrane system and three membrane types (e.g., MF, UF, and NF) on TCE removal and water quality purification, water samples were analyzed for water quality indicating parameters (described in "Groundwater sampling and analyses") during the 


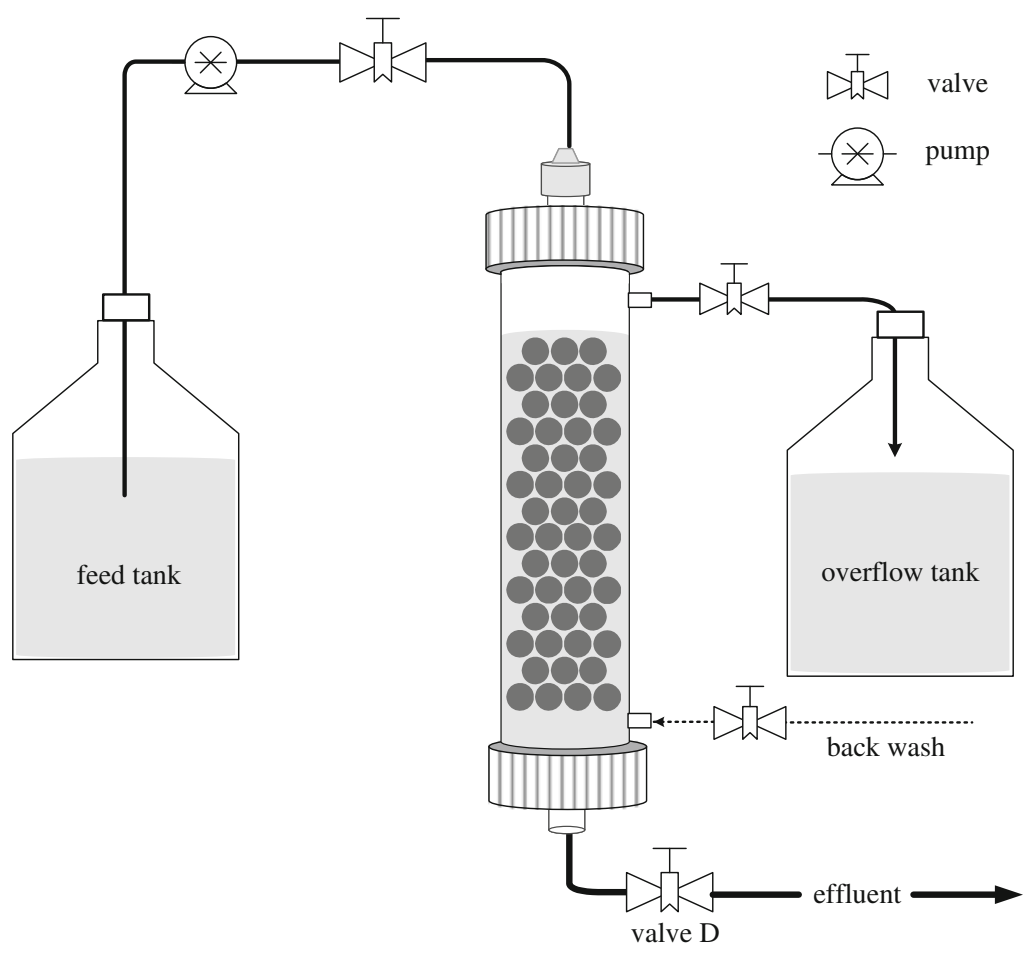

(1)
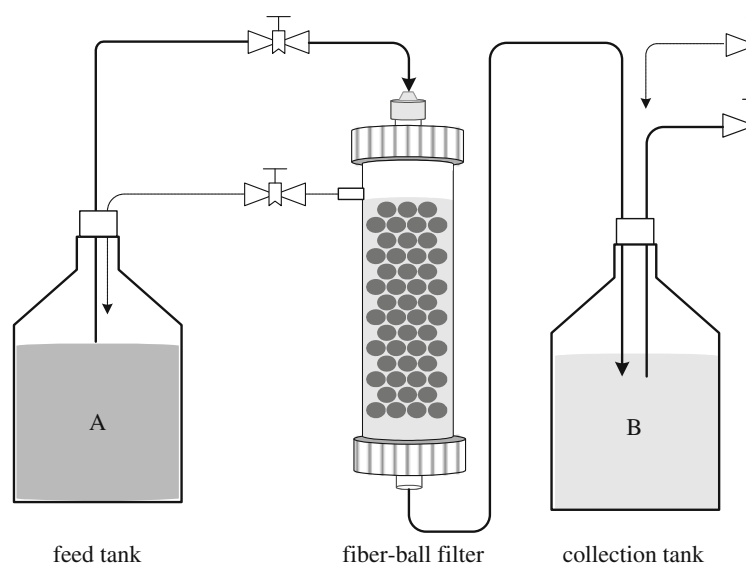

(2)

Fig. 1 Schematic diagram showing the (1) fiber ball filtration system and (2) hybrid membrane system

Table 1 The operational conditions of the fiber ball filtration system

\begin{tabular}{ll}
\hline Item & Value \\
\hline Depth of filter (mm) & 245 \\
Depth of fiber ball (mm) & 180 \\
Velocity of filtration (m/s) & 0.5 \\
Moisture value (\%) & 85.1 \\
EBCT (min) & 0.32
\end{tabular}

EBCT of fiber ball filter was described using the following equation: EBCT $(\min )=V / Q$

$E B C T$ empty bed contact time, $V$ volume of fiber ball $\left(\mathrm{m}^{3}\right), Q$ the flow rate of fiber filtration $(\mathrm{L} / \mathrm{min})$ operational period of the pilot-scale study. The membrane samples collected from different locations were analyzed by the scan electron microscopy (SEM) to investigate the variations in membrane surface formation. The efficiency of TCE treatment by different types of membranes was also investigated.

Membrane resistance analysis

In the TCE tolerance test, different TCE concentrations $(1,6,8$, and $10 \mathrm{mg} / \mathrm{L})$ were used to evaluate the removal efficiencies by cellulose acetate (CA) NF membrane. 
Table 2 Characteristics of different types of membrane modules

\begin{tabular}{|c|c|c|c|c|c|c|c|}
\hline \multirow[t]{2}{*}{ Membrane } & \multirow[t]{2}{*}{ Material } & \multirow[t]{2}{*}{$\mathrm{pH}$} & \multirow[t]{2}{*}{ Maximum temperature $\left({ }^{\circ} \mathrm{C}\right)$} & \multicolumn{3}{|c|}{ Operating pressure range } & \multirow[t]{2}{*}{ MWCO (Da) } \\
\hline & & & & $\mathrm{Bar}$ & $\chi$ & $\mathrm{kg} / \mathrm{cm}^{2}$ & \\
\hline MF & PS & $2-11$ & 50 & $2-6$ & $30-150$ & $2.1-10.5$ & $5 \times 10^{5}$ \\
\hline UF & TFC & $2-11$ & 50 & $4.6-26.6$ & $70-400$ & $4.9-28.1$ & 1,000 \\
\hline $\mathrm{NF}$ & CA & $5-6.5$ & 30 & $6-13.3$ & $60-200$ & $4.2-14.1$ & 200 \\
\hline
\end{tabular}

$P S$ polystyrene, $T F C$ thin film composite, $C A$ cellulose acetate, $M W C O(D a)$ molecular weight cut-off (Dalton)

In the test, water samples were collected when $20,40,60$, 70 , and $80 \%$ of recovery were obtained (Eq. 1).

Recovery $(\%)=\frac{\text { volume of permeate }(\mathrm{V})}{\text { volume of feed }(\mathrm{V})} \times 100 \%$

At the end of the membrane experiment, water samples were also analyzed for TCE rejection, flux, and recovery of permeate. Membrane samples were collected and analyzed for the surface formation using FEI Quanta 200 environmental scanning electron microscope (ESEM) and energy-dispersive spectroscope (EDS). The membrane resistances were determined using the normalized flux $\left(J / J_{0}\right)$ described in the following equation (Fan et al. 2011).

Normalized flux $=\frac{J}{J_{0}}$

$J$ is the running flux; $J_{0}$ the thirst flux $(1 \mathrm{~min})$. Flux $=\frac{Q_{\mathrm{p}}}{h \cdot A}$ $Q_{\mathrm{p}}$ is the volume of permeate (L) $h$ the time $A$ is the membrane surface $\left(\mathrm{m}^{2}\right)$

\section{Results and discussion}

Groundwater analysis

Table 3 shows the characteristics of the groundwater collected from the contaminated area of the TCE-spill site. Because membrane unit was used in the hybrid treatment system, the corrosion and biological scaling potentials were evaluated. Thus, except of the TCE concentration, other water quality indicators (e.g., solid, inorganic compounds, TBC, TOC) were analyzed.

Results show that the averaged $\mathrm{pH}$, turbidity, SS, $\mathrm{NH}_{3}^{+}$- N, TDS, and conductivity were 7.2, $34 \mathrm{NTU}, 1,052$, $0.013,775 \mathrm{mg} / \mathrm{L}$, and $293 \mu \mathrm{S} / \mathrm{cm}$, respectively. The measured alkalinity and hardness of the tested groundwater had average concentrations of 339 and $366 \mathrm{mg} / \mathrm{L}$, respectively. This indicates that the site groundwater contained high concentrations of solids and alkalinity. The comparatively higher conductivity, SS, and TDS values also reveal that the groundwater needed to be pre-treated before further purified by RO system.
Table 3 Characteristics of the site groundwater

\begin{tabular}{|c|c|c|c|}
\hline Parameter & MW & $\mathrm{A}^{\mathrm{a}}$ & $\mathrm{B}^{\mathrm{b}}$ \\
\hline Temperature $\left({ }^{\circ} \mathrm{C}\right)$ & $28.7 \pm 1.4^{\mathrm{c}}$ & - & - \\
\hline $\mathrm{pH}$ & $7.2 \pm 0.6$ & - & - \\
\hline $\mathrm{DO}(\mathrm{mg} / \mathrm{L})$ & $3.48 \pm 0.4$ & - & - \\
\hline Turbidity (NTU) & $34 \pm 14$ & - & - \\
\hline $\mathrm{SS}(\mathrm{mg} / \mathrm{L})$ & $1,052 \pm 94$ & - & - \\
\hline Conductivity & $293 \pm 18$ & - & - \\
\hline TDS (mg/L) & $775 \pm 59$ & 1,250 & - \\
\hline TOC (mg/L) & $1.34 \pm 0.5$ & - & - \\
\hline $\mathrm{NH}_{3}^{+}-\mathrm{N}-\mathrm{N}(\mathrm{mg} / \mathrm{L})$ & $0.013 \pm 0.006$ & 0.250 & - \\
\hline $\mathrm{NO}_{2}^{-}(\mathrm{mg} / \mathrm{L})$ & $0.005 \pm 0.001$ & - & 1 \\
\hline $\mathrm{NO}_{3}^{-}(\mathrm{mg} / \mathrm{L})$ & $4.05 \pm 0.83$ & 25.0 & 10 \\
\hline $\mathrm{SO}_{4}^{2-}(\mathrm{mg} / \mathrm{L})$ & $167 \pm 21$ & 625 & - \\
\hline $\mathrm{Cl}^{-}(\mathrm{mg} / \mathrm{L})$ & $26.3 \pm 4.5$ & 625 & - \\
\hline Alkalinity $\left(\mathrm{mg} / \mathrm{L}\right.$ as $\left.\mathrm{CaCO}_{3}\right)$ & $339 \pm 20$ & - & - \\
\hline Hardness $\left(\mathrm{mg} / \mathrm{L}\right.$ as $\left.\mathrm{CaCO}_{3}\right)$ & $366 \pm 25$ & 750 & - \\
\hline TCE (mg/L) & $0.85 \pm 0.11$ & - & 0.05 \\
\hline $\mathrm{Fe}(\mathrm{mg} / \mathrm{L})$ & $0.99 \pm 0.12$ & 1.50 & - \\
\hline $\operatorname{Mn}(\mathrm{mg} / \mathrm{L})$ & $0.16 \pm 0.06$ & 0.25 & - \\
\hline $\mathrm{TBC}(\mathrm{CFU} / \mathrm{mL})$ & $2.0 \times 10^{4} \pm 3.1 \times 10^{3}$ & - & - \\
\hline
\end{tabular}

${ }^{\mathrm{a}} \mathrm{A}=$ Taiwan 2 nd class groundwater pollution monitoring standards

${ }^{\mathrm{b}} \mathrm{B}=$ Taiwan 2nd class groundwater pollution control standards

c Mean \pm SD

- , not available

The measured TBC and TOC in groundwater were $1.95 \times 10^{4} \mathrm{CFU} / \mathrm{mL}$ and $1.4 \mathrm{mg} / \mathrm{L}$, respectively. The TBC and TOC concentrations indicate that the biological fouling potential was relatively high. The averaged TCE concentration in site groundwater was approximately $0.85 \mathrm{mg} / \mathrm{L}$, and its daughter compounds [dichloroethene (DCE) and vinyl chloride (VC)] were not detected. This might reveal that the intrinsic reductive dechlorination of TCE was not significant. The low $\mathrm{Fe}$ and $\mathrm{Mn}$ concentrations $(<1 \mathrm{mg} / \mathrm{L})$ and high DO concentration $(3.48 \mathrm{mg} / \mathrm{L})$ in groundwater also suggest that the site groundwater was under aerobic and oxidized conditions, which limited the possible $\mathrm{Fe} / \mathrm{Mn}$ fouling on the membrane surface. 
Treatment efficiency and filtration rate using FF

Figure 2 presents the turbidity removal efficiency through FF unit. Results show that up to $95-99 \%$ of turbidity removal efficiencies were observed when three different initial turbidity values $(61,177$, and 370 NTU) and three different filter velocities $(6.1,15.3$, and $27.5 \mathrm{~m} / \mathrm{h}$ ) were applied. The turbidity value dropped to below 3 NTU after the application of FF system. The results indicate that the FF system would be able to remove the solids in groundwater effectively. Because the pore size of the fiber ball is less than $5 \mathrm{~nm}$, the silt and sand particles in groundwater can be removed via the FF process.

Results from other studies show that TCE in solution could be adsorbed onto porous materials in solution, which caused the decrease in TCE concentrations in the supernatant (Mudliar et al. 2010; Wei et al. 2010). Thus, sorption was the one of the major mechanisms, which caused the decrease in TCE concentrations in solution containing porous materials (Mudliar et al. 2010; Wei et al. 2010). Huang et al. (2010) used different types of PAC to evaluate the adsorption mechanisms using porous materials. Their results indicated that the adsorption of natural organic matter (NOM) in water by porous materials would cause the occurrence of competitive adsorption mechanism, which resulted in the decease in TCE removal. Li et al. (2003) indicated the competitive adsorption contained two major mechanisms including direct site competition and pore constriction/blockage with porous materials. Results from this study show that approximately 4.5, 6.7, and $92.6 \%$ of TOC, TDS, and SS were removed through the FF unit, respectively (Table 4). This indicates that adsorption of NOM and inorganic particles in groundwater by FF might cause a drop of TCE removal efficiency due to the possible competitive adsorption mechanism. Thus,

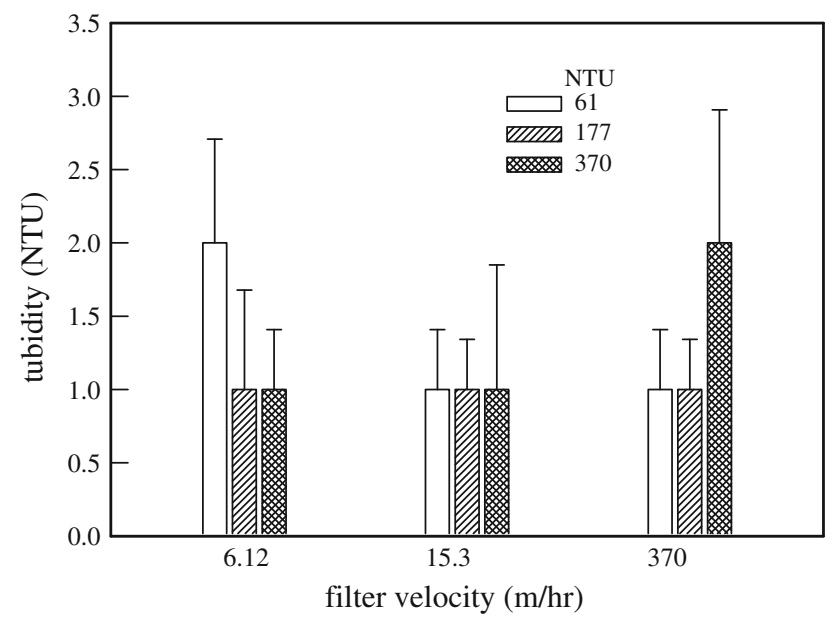

Fig. 2 The removal efficiency of turbidity by three levels velocities on fiber ball filter significant TCE removal was observed at the beginning of the FF operation, however, complete TCE removal could not be obtained.

\section{Effect of different types membrane on TCE removal}

Figure 3 presents the treatment efficiency of TCE $(1.0 \mathrm{mg} /$ L) using different types of membrane operated in room temperature $\left(26^{\circ} \mathrm{C}\right)$ with filter pressure of $4.1 \mathrm{~kg} / \mathrm{cm}^{2}$. The MWCO (molecular weight cut-off) for MF, UF, and NF membranes were $500 \mathrm{~K}, 1 \mathrm{~K}$, and $200 \mathrm{Da}$, respectively. Thus, higher TCE rejection rate was observed when NF was used as the filtration membrane. The main TCE removal mechanism in the MF and UF systems was membrane filtration (Mudliar et al. 2010; Zhao et al. 2011). However, TCE was removed through the sieving electrostatic repulsion force and dissolution and diffusion mechanisms in the NF system (Kumar et al. 2008; Zhao et al. 2011). Therefore, it is possible that sieving electrostatic repulsion force, dissolution, and diffusion were also the TCE removal mechanisms when the NF membrane was applied for water treatment. This also caused the different treatment efficiencies of TCE using three different membrane systems (Zhao et al. 2011). Variations in TCE rejection efficiency versus recovery rate are also shown in Fig. 3. Results show that the TCE rejection efficiencies increased as the membrane recovery rate increased. The observed TCE rejection efficiencies for MF, UF, and NF membranes were 95.8, 96.1, and $98.2 \%$, respectively, when high recovery rate $(80 \%)$ was used. The results indicate that a higher TCE separation efficiency could be obtained when a lower MWCO membrane was used. Similar results were also reported by Fersi et al. (2009). Significant linear correlations between the TCE rejection efficiency and recovery rate were observed although different types of membranes were used.

\section{Membrane tolerance test of different levels TCE concentration}

In this study, the effectiveness of NF membrane on TCE removal was evaluated. Four different initial TCE concentrations $(1,6,8$, and $10 \mathrm{mg} / \mathrm{L})$ were tested. Figure 4 shows the variations in TCE rejection versus the recovery rate with varied initial TCE concentrations $(1,6,8$, and $10 \mathrm{mg} / \mathrm{L}$ ). Results indicate that up to 96.6 and $98.2 \%$ of TCE rejections were observed when the recover rates were 20 and $80 \%$ with the initial TCE concentration of $1.0 \mathrm{mg} / \mathrm{L}$, respectively. Results also show approximately 75.3 and $78.6 \%$ of TCE rejections were observed when the recover rates were 20 and $80 \%$ with the initial TCE concentration of $10 \mathrm{mg} / \mathrm{L}$, respectively. Results indicate that higher TCE rejection can be obtained when lower TCE concentration 
Table 4 Results of groundwater treatment efficiencies using the hybrid treatment system

\begin{tabular}{|c|c|c|c|c|c|c|c|c|}
\hline Parameters & Raw water & $\mathrm{FF}$ & $\mathrm{R}^{\mathrm{a}}$ & $\mathrm{FF}+\mathrm{NF}$ & $\mathrm{R}^{\mathrm{b}}$ & $A^{c}$ & $\mathrm{~B}^{\mathrm{d}}$ & $\mathrm{C}^{\mathrm{e}}$ \\
\hline $\mathrm{pH}$ & $7.2 \pm 0.6^{\mathrm{f}}$ & $7.15 \pm 0.3$ & - & $7.1 \pm 0.3$ & - & $6.0-8.5$ & $6.0-8.5$ & $6.0-8.5$ \\
\hline Turbidity (NTU) & $34 \pm 14$ & $1.0 \pm 0.1$ & 95.0 & $<1$ & 99.9 & $<0.5$ & $<5$ & $<5$ \\
\hline $\mathrm{SS}(\mathrm{mg} / \mathrm{L})$ & $1,052 \pm 94$ & $78 \pm 5$ & 92.6 & $<1$ & 99.9 & $<2$ & $<2$ & $<2$ \\
\hline TOC (mg/L) & $1.34 \pm 0.5$ & $1.28 \pm 0.2$ & 4.5 & $0.4 \pm 0.1$ & 70.0 & $<3$ & $<5$ & - \\
\hline Conductivity $(\mu \mathrm{S} / \mathrm{cm})$ & $293 \pm 18$ & $263 \pm 15$ & 10.2 & $125 \pm 12$ & 57.3 & $<250$ & $<300$ & - \\
\hline TDS (mg/L) & $775 \pm 59$ & $723 \pm 32$ & 6.7 & $77 \pm 19$ & 90.1 & $<100$ & $<800$ & - \\
\hline $\mathrm{NH}_{3}^{+}-\mathrm{N}(\mathrm{mg} / \mathrm{L})$ & $0.013 \pm 0.006$ & $0.01 \pm 0.002$ & 23.1 & $0.001 \pm 0.001$ & 92.3 & - & $<35$ & - \\
\hline $\mathrm{NO}_{2}^{-}(\mathrm{mg} / \mathrm{L})$ & $0.005 \pm 0.001$ & $0.003 \pm 0.001$ & 40.0 & $0.002 \pm 0.001$ & 60.0 & $<50$ & $<400$ & $<850$ \\
\hline $\mathrm{NO}_{3}^{-}(\mathrm{mg} / \mathrm{L})$ & $4.05 \pm 0.83$ & $3.82 \pm 0.65$ & 5.7 & $3.75 \pm 0.47$ & 7.4 & - & - & - \\
\hline $\mathrm{SO}_{4}^{2-}(\mathrm{mg} / \mathrm{L})$ & $167 \pm 21$ & $156 \pm 16$ & 6.6 & $5.1 \pm 2.1$ & 96.9 & $<15$ & - & - \\
\hline $\mathrm{Cl}^{-}(\mathrm{mg} / \mathrm{L})$ & $26.3 \pm 4.5$ & $23.8 \pm 2.4$ & 9.5 & $3.82 \pm 1.1$ & 85.5 & $<5$ & $<50$ & - \\
\hline Alkalinity $\left(\mathrm{mg} / \mathrm{L}\right.$ as $\left.\mathrm{CaCO}_{3}\right)$ & $339 \pm 20$ & $334 \pm 17$ & 1.5 & $59 \pm 4$ & 82.6 & $<20$ & $<200$ & - \\
\hline Hardness $\left(\mathrm{mg} / \mathrm{L}\right.$ as $\left.\mathrm{CaCO}_{3}\right)$ & $366 \pm 25$ & $346 \pm 17$ & 5.5 & $20 \pm 3$ & 94.5 & - & - & - \\
\hline TCE (mg/L) & $0.85 \pm 0.11$ & $0.035 \pm 0.002$ & 95.9 & $0.023 \pm 0.001$ & 97.3 & $<0.04$ & $<0.3$ & - \\
\hline $\mathrm{Fe}(\mathrm{mg} / \mathrm{L})$ & $0.99 \pm 0.12$ & $0.005 \pm$ & 99.5 & $<0.001$ & 99.9 & $<0.05$ & $<0.1$ & - \\
\hline $\mathrm{Mn}(\mathrm{mg} / \mathrm{L})$ & $0.16 \pm 0.06$ & $0.052 \pm 0.012$ & 67.5 & $0.049 \pm 0.01$ & 69.4 & $<0.5$ & $<5$ & $<5$ \\
\hline TBC (CFU/mL) & $2.0 \times 10^{4} \pm 3.1 \times 10^{3}$ & $9.9 \times 10^{3} \pm 1.2 \times 10^{3}$ & 49.2 & $75 \pm 28$ & 99.6 & - & $<3$ & - \\
\hline
\end{tabular}

${ }^{\mathrm{a}} \mathrm{R}=$ FF removal efficiency

${ }^{\mathrm{b}} \mathrm{R}=$ total removal efficiency

c $\mathrm{A}=$ boiler water use standards

${ }^{\mathrm{d}} \mathrm{B}=$ cooling water use standards

${ }^{\mathrm{e}} \mathrm{C}=$ irrigation water use standards developed by Water Resources Agency, Taiwan

${ }^{\mathrm{f}}$ Mean $\pm \mathrm{SD}$

,- not available

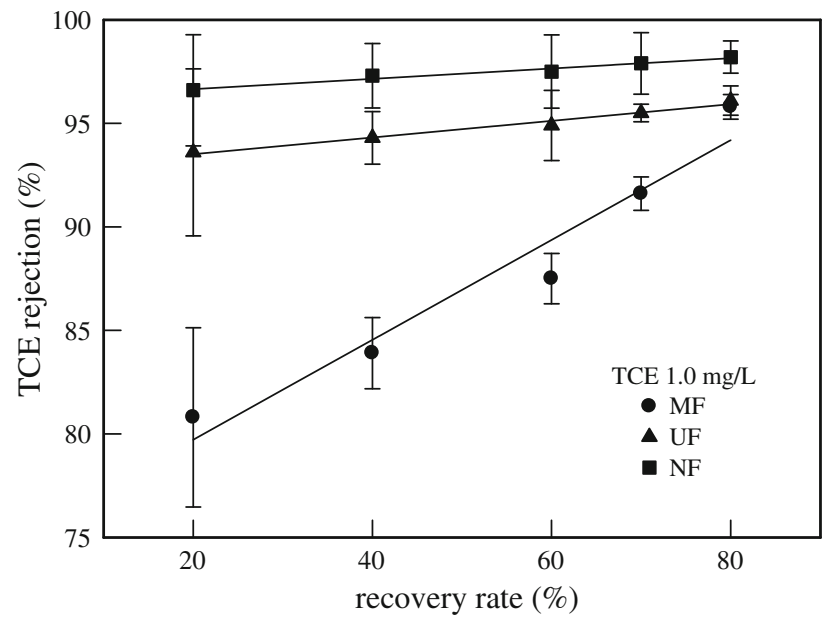

Fig. 3 Variations in TCE rejection versus recovery rate using different membranes types (pressure $4.1 \mathrm{~kg} / \mathrm{cm}^{2}$ )

$(1 \mathrm{mg} / \mathrm{L})$ was applied. Significant decrease in TCE rejection was obtained when NF was used to treat higher TCE concentration (e.g., $10 \mathrm{mg} / \mathrm{L}$ ). Al-Amoudi (2010) indicated that the membrane pore size would shrink due to the inefficient dissolution rate. Yang et al. (2001) reported that residual organic solvent would remain on the NF

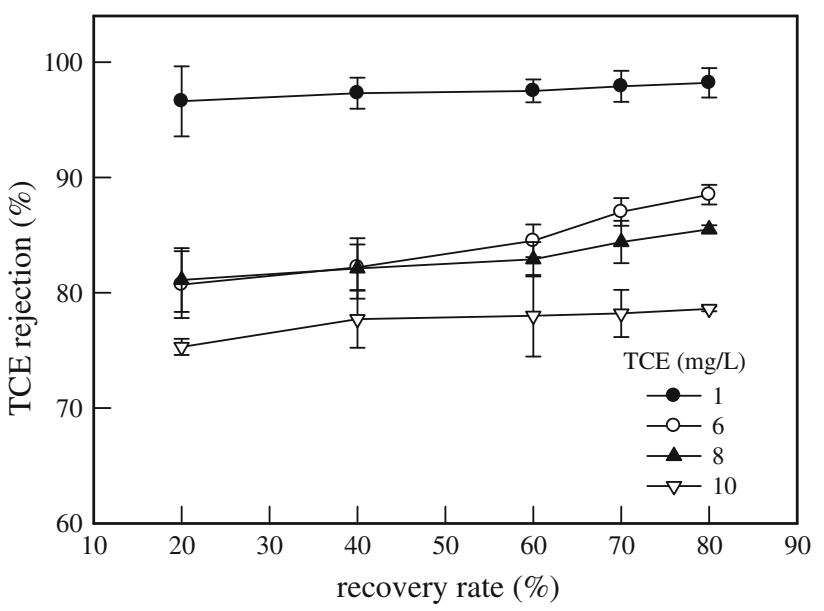

Fig. 4 Variations in TCE rejection versus the recovery rate using NF membrane with different initial TCE concentrations

membrane surface and cause the destruction of functional groups of membrane materials when high concentration of organic solvent was treated. This makes the NF membrane became polarized. Fersi et al. (2009) indicated that the polarization of the membrane would make up cake layers on membrane surface rapidly, which caused the reduction 

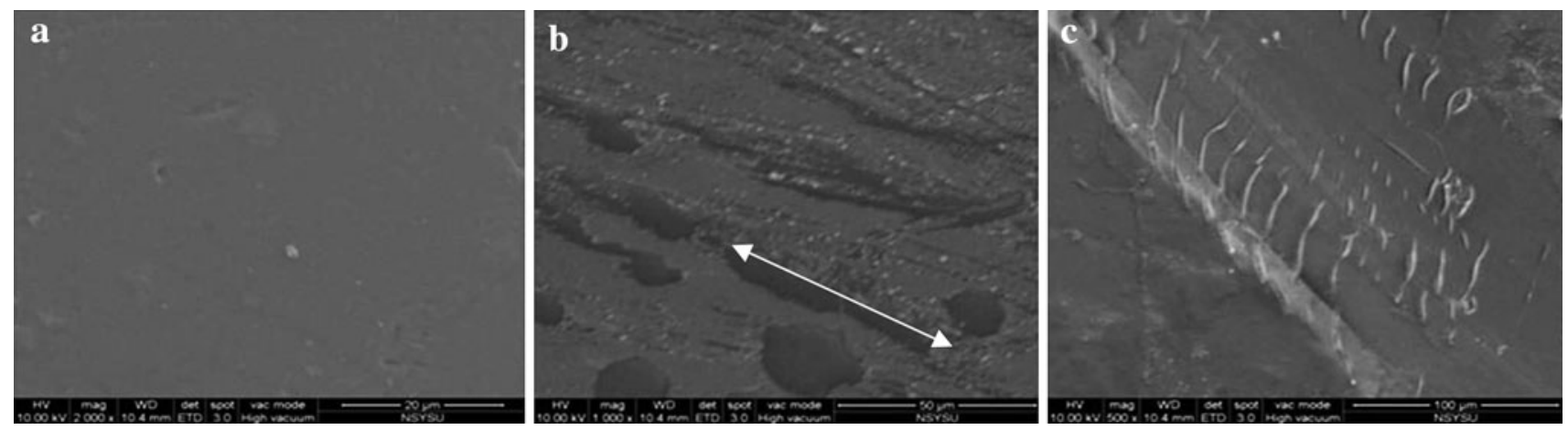

Fig. 5 ESEM photographs of NF membranes before and after the groundwater treatment [a before treatment $(\times 2,000), \mathbf{b}, \mathbf{c}$ after treatment $(\mathbf{b} \times 1,000, \mathbf{c} \times 500)]$

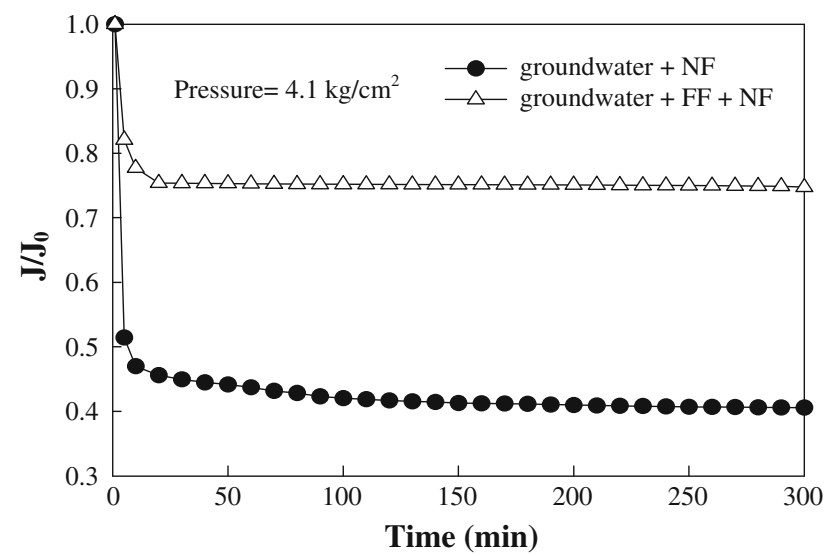

Fig. 6 Variation in membrane flux versus time in two different tests

of flux. Liang et al. (2007) also reported that the pore size on membrane surface would contract due to the residual organic contaminant on the membrane surface, and this would increase the rejection rate of contaminates. Thus, using membrane to treat highly organic solvent (e.g., TCE) contaminated groundwater (or wastewater) (e.g., TCE $10 \mathrm{mg} / \mathrm{L}$ ) would not achieve satisfactory contaminant rejection efficiency.

Application of hybrid treatment system on site groundwater purification

In this study, the developed hybrid membrane system (FF unit followed by NF unit) was applied for the contaminated groundwater (collected from the studied TCE-contaminated site) reclamation. Table 4 presents the removal efficiencies of turbidity, TDS, SS, conductivity, TOC, $\mathrm{NH}_{3}^{+}-\mathrm{N}, \mathrm{NO}_{2}^{-}$, $\mathrm{NO}_{3}^{-}, \mathrm{SO}_{4}^{2-}, \mathrm{Cl}^{-}$, alkalinity, hardness, $\mathrm{Fe}, \mathrm{Mn}, \mathrm{TBC}$, and TCE after the treatment by the hybrid treatment membrane system. Results show that up to $97.3 \%$ of TCE, $99.9 \%$ of turbidity, and $99.9 \%$ of SS could be removed by the hybrid treatment system. Results indicate that the hybrid system could effectively remove TCE, inorganic particles, turbidity, and TBC from groundwater and improve the groundwater quality significantly. The treated groundwater can meet the use for boiler water, cooling water, and irrigation use and groundwater remediation standards, and also minimize the possible membrane fouling if a RO membrane is applied after the hybrid system for further treatment. However, results show that no significant drops for $\mathrm{NO}_{3}^{-}$, $\mathrm{SO}_{4}^{2-}$, and alkalinity after treatment by the hybrid system. This indicates that FF and NF are not effective on dissolved inorganic chemicals removal.

Figure 5a shows the ESEM photograph of NF membrane before the application on groundwater treatment. Figure $5 b$ is the ESEM photograph $(1,000 \times)$ showing the retained TCE on the NF membrane surface after the treatment of groundwater with high TCE concentration $(10 \mathrm{mg} / \mathrm{L})$. Figure $5 \mathrm{c}$ shows the damage of the NF membrane surface after the treatment of groundwater with high TCE concentration $(10 \mathrm{mg} / \mathrm{L})(500 \times)$. The retained TCE would cause the decrease in normalized flux. Furthermore, the retained TCE would also result in the damage of the membrane, which would increase the pore size of membrane, and thus, cause the decrease in TCE rejection rate.

Figure 6 shows the membrane flux of two different treatment tests. In the first test, no FF unit was applied and the NF unit was used for groundwater treatment directly and the flow pressure was controlled at $4.1 \mathrm{~kg} / \mathrm{cm}^{2}$ in NF membrane module. Results show that the normalized flux for the $\mathrm{NF}$ and $\mathrm{FF}+\mathrm{NF}$ processes were 0.42 and 0.75 $\left(J / J_{0}\right)$, respectively. Approximately $46.6 \%$ of flux drop was observed when NF membrane was used along compared to the system using FF as the first treatment stage. This indicates that the appropriate pre-treatment process $(\mathrm{FF}+\mathrm{NF})$ would ensure a high permeate flux of membrane and also extend the life of NF membrane. If proper pre-treatment is applied, the lifetime of NF can be extended to 3 years (Huang et al. 2011). Results indicate that the hybrid pretreatment system is appropriate for the reclamation of TCE and fine-particle contained groundwater treatment before the groundwater is further purified for reuse. 


\section{Conclusion}

In this laboratory pilot-scale study, a hybrid treatment system contained FF unit followed by NF membrane unit was developed to treat TCE-contaminated groundwater before RO unit was applied for further domestic and industrial uses. Conclusions of this study include the following:

1. FF could effectively remove groundwater turbidity to less than 3 NTU while filtration rates were 6.1, 15.3, and $27.5 \mathrm{~m} / \mathrm{h}$ with initial turbidity value up to 61,177 , and $370 \mathrm{NTU}$, respectively.

2. More than $97.3 \%$ of TCE, $99.9 \%$ of turbidity, and $99.9 \%$ of SS could be removed by the hybrid treatment system when the initial TCE, conductivity, and SS of the tested groundwater were approximately $850 \mu \mathrm{g} / \mathrm{L}, 34 \mu \mathrm{S} / \mathrm{cm}$, and $1,052 \mathrm{mg} / \mathrm{L}$, respectively, with an operational pressure of $4.1 \mathrm{~kg} / \mathrm{cm}^{2}$. This indicates that the developed FF and NF membrane system is able to reduce the TCE and solid concentrations to meet the water reuse and groundwater remediation standards.

3. Up to $98.2 \%$ of TCE rejection was observed when NF membrane was used for TCE removal with the recover rate of $80 \%$ and initial TCE concentration of $1.0 \mathrm{mg} / \mathrm{L}$. Results also indicate that high TCE concentration $(10 \mathrm{mg} / \mathrm{L})$ would increase the pore size of NF, and thus, cause the decrease in TCE rejection rate.

4. Approximately $46.6 \%$ of flux drop was observed when NF membrane was used along compared to the system using $\mathrm{FF}$ as the first treatment stage.

5. The TCE removal mechanism in the FF process was mainly due to adsorption. However, sieving electrostatic repulsion force and solution-diffusion mechanisms were the major causes of TCE removal in the NF unit.

6. The proposed hybrid treatment membrane system scheme would be expected to provide a more effective method using FF as the treatment unit followed by UF membrane system to purify TCE-contaminated groundwater for the groundwater treatment and water reuse purpose.

Acknowledgments This project was funded in part by Taiwan National Science Council (Grant no. 98-2622-E-110-002-CC3). The authors would like to express their sincere thanks to the personnel at National Science Council, Nan-Zih Industrial Park, and Capital Engineering Corp., Taiwan for their assistance and support throughout this project.

\section{References}

Al-Amoudi AS (2010) Factors affecting natural organic matter (NOM) and scaling fouling in NF membranes: a review. Desalination 259(1-3):1-10
APHA (American Public Health Association), 2005. American water works association \& water environment federation. Standard methods for the examination of water and wastewater, 21st ed. Washington, D.C., USA

Fan LH, Nguyen T, Roddick FA, Harris JL (2008) Low-pressure membrane filtration of secondary effluent in water reuse: pretreatment for fouling reduction. J Membr Sci 320(1-2):135-142

Fan L, Harris JL, Roddick FA, Booker NA (2011) Influence of the characteristics of natural organic matter on the fouling of microfiltration membranes. Water Res 35:4455-4463

Fersi C, Gzara L, Dhahbi M (2009) Flux decline study for textile wastewater treatment by membrane processes. Desalination 244(1-3):321-332

Hoinkis J, Panten V (2008) Wastewater recycling in laundries-From pilot to large-scale plant. Chem Eng Prog 47(7):1159-1164

Howell JA (2004) Future of membranes and membrane reactors in green technologies and for water reuse. Desalination 162(1-3):1-11

Huang L, Yang Z, Li B, Hu J, Zhang W, Ying WC (2010) Granular activated carbon adsorption process for removing trichloroethylene from groundwater. AIChE J 57(2):542-550

Huang CJ, Yang BM, Chen KS, Chang CC, Kao CM (2011) Application of Membrane Technology on Semiconductor Wastewater Reclamation: a Pilot-scale Study. Desalination 278(1-3):203-210

Kan CC, Chen WH, Wan MW, Phatai P, Wittayakun J, Li KF (2012) The preliminary study of iron and manganese removal from groundwater by $\mathrm{NaOCl}$ oxidation and $\mathrm{MF}$ filtration. Sustain. Environ. Res. 22(1):25-30

Kumar A, Dewulf J, Langenhove HV (2008) Membrane-based biological waste gas treatment. Chem Eng J 136:82-91

Li Q, Snoeyink VL, Mariãas BJ, Campos C (2003) Elucidating competitive adsorption mechanisms of atrazine and NOM using model compounds. Water Res 37(4):773-784

Liang C, Bruell C, Albert MF, Cross PE, Ryan DK (2007) Evaluation of reverse osmosis and nanofiltration for in situ persulfate remediated groundwater. Desalination 208(1-3):238-259

Mudliar S, Giri B, Padoley K, Satpute D, Dixit R, Bhatt P, Pandey R, Juwarkar A, Vaidya A (2010) Bioreactors for treatments of VOCs and odours: a review. J Environ Manage 91(6):1039-1054

Peiris RH, Budman H, Moresoli C, Legge RL (2010) Understanding fouling behaviour of ultrafiltration membrane processes and natural water using principal component analysis of fluorescence excitation-emission matrices. J Membr Sci 357(1):62-72

Taiwan Environmental Protection Administration (TEPA) (2011) Soil and Groundwater Remediation Act. Taipei City, Taiwan

Tsai TT, Kao CM, Surampalli Rao Y, Weng CH, Liang SH (2010) Treatment of TCE-contaminated groundwater using Fenton-like oxidation activated with basic oxygen furnace slag. J Environ Eng ASCE 136(2):288-294

Tsai TT, Kao CM, Wang JY (2011) Remediation of TCE-contaminated groundwater using acid/BOF slag enhanced chemical oxidation. Chemosphere 83(3):687-692

Vogel D, Simon A, Alturki AA, Bilitewski B, Price WE, Nghiem LD (2010) Effects of fouling and scaling on the retention of trace organic contaminants by a nanofiltration membrane: the role of cake-enhanced concentration polarization. Sep Purif Technol 73(2):256-263

Vrouwenvelder JS, Graf von der Schulenburg DA, Kruithof JC, Johns ML, van Loosdrecht MCM (2009) Biofouling of spiral-wound nanofiltration and reverse osmosis membranes: a feed spacer problem. Water Res 43(3):583-594

Wei Z, Seo Y (2010) Trichloroethylene (TCE) adsorption using sustainable organic mulch. J Hazard Mater 181(1):147-153

Xie Y, Li S, Wu K, Wang J, Liu G (2011) A hybrid adsorption/ ultrafiltration process for perchlorate removal. J Membr Sci 366(2):237-244 
Xue G, Gao P, Dai XM, Wang YH (2008) Study on ultrafiltration and nanofiltration combined with pre-treatment of micro-flocculation fiber ball used in hotel bath wastewater treatment and comprehensive reuse. Technol Water Treat 34(1):30-36

Xue G, Ma ZY, Meng YP, Xie L (2009) Study on algae removal by micro-flocculation and high stretch yarn Terylene fiber ball filtration. China Water Wastewater 25(1):52-54

Yang XJ, Livingston AG, Freitas dos Santos L (2001) Experimental observations of nanofiltration with organic solvents. J Membr Sci 190(1):45-55

Yaroshchuk A, Lladó XM, Llenas L, Rovira M, Pablo JD (2011) Solution-diffusion-film model for the description of pressure- driven trans-membrane transfer of electrolyte mixtures: one dominant salt and trace ions. J Membr Sci 368(1):192-201

Zeng YB, Zhang XL, Yang DW, Ran SY, Zhu ZM (2007) Application of modified fiber ball in reuse of heavy oil wastewater as boiler water. Ind Water Wastewater 38(1):66-69

Zermeño BB, Moctezuma E, García-Alamilla R (2011) Photocatalytic degradation of phenol and 4-chlorophenol with titania, oxygen and ozone. Sustain Environ Res 21(5):299-305

Zhao Y, Liu Z, Liu F, Li Z (2011) Cometabolic degradation of trichloroethylene in a hollow fiber membrane reactor with toluene as a substrate. J Membr Sci 372(1-2):322-330 